Open Access

\title{
Correction to: Living for the neighborhood: marginalization and belonging for the second-generation in Berlin and Paris
}

Christine Barwick ${ }^{1}$ and Jean Beaman ${ }^{2^{*}}$

\author{
* Correspondence: \\ beamanj@purdue.edu \\ The original article can be found \\ online at https://doi.org/10.1186/ \\ s40878-018-0105-3 \\ ${ }^{2}$ Purdue University, West Lafayette, \\ IN 47907, USA
}

\section{Correction to: Comparative Migration Studies (2019) 7:1 https://doi.org/10.1186/s40878-018-0105-3}

Following publication of the original article (Barwick \& Beaman, 2019), it was reported that the article title contained an error. The incorrect article title was 'Living for the city: marginalization and belonging for the second-generation in Berlin and Paris'. The corrected article title is 'Living for the neighborhood: marginalization and belonging for the second-generation in Berlin and Paris'. The original publication of this article has been updated to correct this.

\section{Author details \\ ${ }^{1}$ Centre Marc Bloch, Friedrichstrasse 191, 10117 Berlin, Germany. ${ }^{2}$ Purdue University, West Lafayette, IN 47907, USA.}

Received: 29 January 2019 Accepted: 29 January 2019

Published online: 06 February 2019

\section{Reference}

Barwick, C., \& Beaman, J. (2019). Living for the neighborhood: Marginalization and belonging for the second-generation in Berlin and Paris. Comparative Migration Studies, 7. https://doi.org/10.1186/s40878-018-0105-3. 